\section{ERS School first educational research seminar: weathering the winds of change through medical education}

In this uncertain time of fast-moving societal, economic and technological changes reshaping the medical profession in general, the respiratory specialty is presented with significant challenges and, at the same time, distinct and valuable opportunities.

The movement of both patients and doctors within the European Union has focused even greater attention on the competence of doctors and their fitness to practice. HoRsLeY et al. [1] describe the variation between continuing professional development systems across EU countries and argues for harmonisation of accreditation systems to simplify this process.

At the same time, technological changes have introduced new concepts and challenges in how we conduct medical education both by instruction and assessment, such as in elearning, simulators and simulation scenarios.

These trends will particularly impact on the practice of respiratory medicine and it is therefore crucial that theprofession keeps pace. This requires particular efforts in education and training.

Medical education reforms then become relevant, and calls for: 1) standardising learning outcomes and individualising the learning process; 2) promoting multiple forms of integration; 3) methods of selfreflection and selfimprovement; and 4) focusing on the progressive formation of the physician's professional identity [2].

These reforms will need to be supported appropriately by the EU and member states. The European Respiratory Society (ERS) is in a unique position to propose EU-wide principles, values and measures. For this reason, the ERS has engaged in a critical selfreflection of the current state of educational policies within the society as well as determining future directions by organising the first ERS educational research seminar.

\section{ERS School educational research seminar}

The ERS School organised an educational research seminar on June 3-4, 2011 in Dublin, Ireland. International experts in medical education and respiratory medicine attended, including colleagues from the American College of Chest Physicians and the American Thoracic Society. They came together to discuss the future trends and challenges of medical education in respiratory medicine. The format was a 2-day seminar comprising eight sessions covering topics such as the evolution of medical education, challenges in educating respiratory health care professionals, harmonisation of medical education in Europe, knowledge transfer, instructional methods including simulation and skills training, e-world and continuing medical education, and eportfolios. Table 1 shows the programme and faculty.

Two discussants were assigned for each session for which they gave their reactions and presented issues. This facilitated the probing of these topics and their relation to

\section{P. Palange}

J-L. Noël ${ }^{2}$

${ }^{1}$ University of Rome "La Sapienza', Dept of Clinical Medicine, Pulmonary Function Unit, Rome Italy

${ }^{2}$ ERS Headquarters, Lausanne, Switzerland

Competing interests None declared.
HERMES syllabus link: F.4, F.5, F.7 


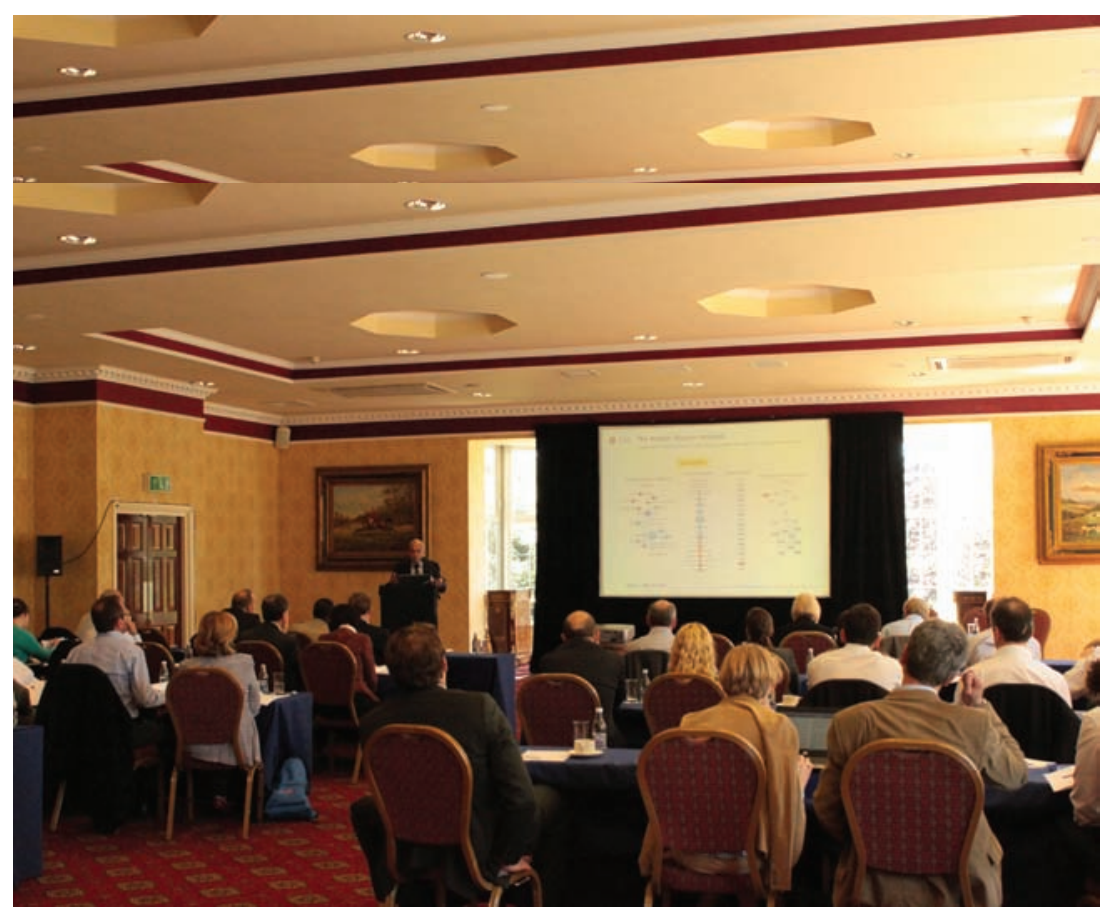

the practice of respiratory medicine and training. Parallel breakout sessions featured relevant topics reflecting the current ERS educational activities: instructional methods, continuing medical education and e-learning.

\section{Discussion points}

The session on the evolution of medical education in the last 100 years highlighted the exciting period we are in with medical education being a new field and, at the same time, meriting a serious and scientific approach. A recent call for a new reform in medical education was discussed with the 100-year anniversary of the
Flexner report which has been the basis of medical education to date [2].

Furthermore, the future of medical education was said to be difficult to predict. At present, there is a great interest in the so-called "P4" (preventive, predictive, personalised, participatory) medicine. However, it is not clear if doctors and nurses in the future will be trained to fulfil the challenges and expectations of the P4 medicine. Because of ageing population, there is no doubt that future doctors and nurses will need to improve their knowledge and skills in areas such as treatment of co-morbidities, rehabilitation and telemedicine. Respiratory doctors and nurses should improve their competence and skills in the management of respiratory critical care and respiratory sleep disorders patients.

Harmonisation was presented as having more advantages. Discussions emphasised on the central problem of equivalence of training across Europe and its implications with increased mobility of health professionals thus rendering the drive for harmonisation essential. Central examinations were widely discussed as playing animportant role whether mandatory orvoluntary. The worth of incorporating these in the curriculum was reflected upon. The HERMES examination was widely discussed with issues on language and assessments for in-training assessment, selfassessment and certification purposes.

An example of knowledge transfer and skills training was presented with patient handovers: translating knowledge from motor racing to healthcare. The session discussed the methods of F1 drivers in their training to actually improve healthcare professional training with positive

\section{Table 1 Educational research seminar programme}

\begin{tabular}{|ll} 
Faculty & Presentation \\
Prof. James McKillop (Glasgow, UK) & $\begin{array}{l}\text { Evolution of medical education in the past century } \\
\text { Challenges in educating respiratory healthcare } \\
\text { professionals in the next } 20 \text { years }\end{array}$ \\
Prof. Paolo Palange (Rome, Italy) & $\begin{array}{l}\text { Pros and cons of harmonisation of medical education } \\
\text { throughout Europe }\end{array}$ \\
Dr Jamiu 0. Busari (Maastricht, The Netherlands) & $\begin{array}{l}\text { Instructional methods: perspectives towards effective } \\
\text { teaching methods for postgraduate respiratory medicine }\end{array}$ \\
Dr Ken R. Catchpole (Oxford, UK) & $\begin{array}{l}\text { Patient handovers within the hospital: translating } \\
\text { knowledge from motor racing to healthcare } \\
\text { Assessment methods: perspectives on international } \\
\text { postgraduate assessment } \\
\text { E-world in medical education: e-learning, e-portfolios etc. } \\
\text { Dr Erik Driessen (Maastricht, The Netherlands) }\end{array}$ \\
Dr Rachel Ellaway (Sudbury, ON, Canada) & $\begin{array}{l}\text { Continuing medical education: how to ensure positive } \\
\text { impact on clinical practice }\end{array}$ \\
Dr Alexandra Cope (London, UK) &
\end{tabular}


outcomes. This leads to the reflection that there are methods to improve on learning processes, minimising errors and teaching. This can be done by looking at and drawing on the lessons of training in other fields.

The assessment methods perspectives on international postgraduate assessment discussed the trend of workplacebased assessments and standardised assessments. This discussion centred on the challenge of actually applying these assessments in the postgraduate setting. Reluctance in introduction of these assessments is due to the limited resources and other logistical and economic problems. A lack of insight into the effort, know-how and professionalism put into the conduct of valid and high-quality assessments was also seen as hindering development.

The instructional methods breakout session considered the needs of trainees, content experts and educators. While it is relatively straight forward for ERS to provide content, the challenge is to adapt delivery methods especially when developing workplace training and learning opportunities in the ever pressurised clinical environment.

With regards to continuing medical education, the discussion focused on the requirement for CME credits and its documentation. Here, there is widespread variation across Europe. The opinion on its effect on improved patient care is divided. Programmes that enable users to measure the impact of any change in practice on their patient group seem most relevant.

The discussion on elearning centred on its usefulness. Without a generic answer, the clear benefits mentioned include its being economic, its usability and being an adjunct to traditional knowledge resources, such as textbooks. Changing learning attitudes were also mentioned such as trainees learning in a group process and the wider availability of educational material on open access resources, such as YouTube.

\section{ERS educational activities}

As a result of the discussions and reflections in the educational research seminar, ERS educational activities will be enhanced. Appropriate instructional methods will be applied to the postgraduate courses, external courses, and Pan-European Network for Study and Clinical Management of Drug-Resistant Tuberculosis (TB-PANNET). The 'train the trainer' approach

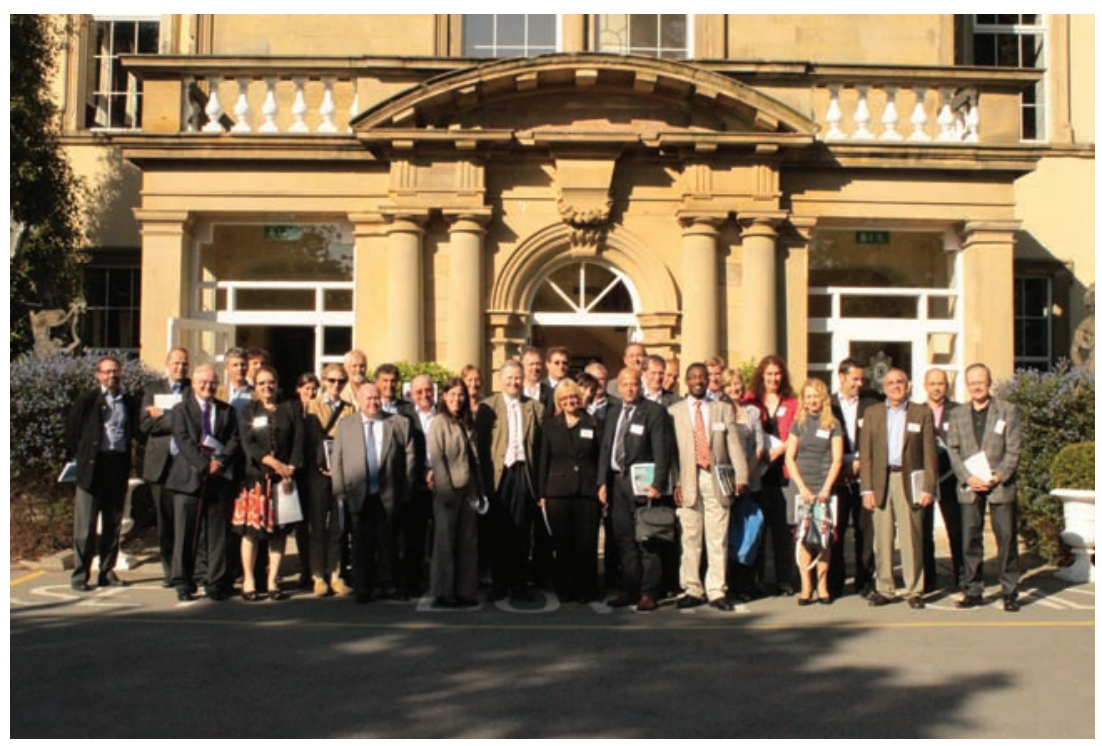

will be emphasised and offered to many respiratory medicine specialists. Continuing medical education will be developed and will not only be based on legal requirements but also on opportunities for self-regulation through self-assessment and recertification. E-learning will be developed and changing learning attitudes kept in mind when developing e-learning courses, or other e-learning activities and offerings.

\section{ERS educational initiative: the HERMES projects}

The HERMES (Harmonised education in respiratory medicine for European specialists) initiative of the ERS is a pillar of the ERS educational activities and serves to provide multiple forms of integration in the training of respiratory specialists. Since 2006, HERMES projects use consensus methods and work with experts in producing educational standards: syllabus, curriculum, European examination and centres of excellence. It is in continuous development and improvement adhering to current medical education theory and principles.

With syllabus and curriculum developments, a balance between knowledge-based, skills-based and attitudes and behaviour competencies is aimed for. This has already begun with the Adult HERMES and Paediatric HERMES projects which have produced syllabi, curricula and diploma examination [3-6]. The ERS Respiratory Handbook concisely covers the Adult HERMES programme content [7]. Equally, the HERMES 
Respiratory Sleep Disorders has just published their syllabus and have begun groundwork on their curriculum [8]. All these training standards have focus on trainees and their training. ERS will focus on and invest in subspecialties, such as critical care and oncology. Emphasis will be on the specific levels of competence. This is already seen with the example of the tertiary skill levels of the paediatric respiratory medicine specialists in Paediatric HERMES and will be further developed with other subspecialties.

The Adult HERMES has recently published criteria for accreditation of ERS European training centres for which the other HERMES projects will follow suit [9].

Recertification will be another priority. There will be active negotiations with EU countries to adopt the HERMES examination as a basis for recertification.

The ERS will also invest in allied professionals for whom training for their specific care pathways in the respiratory specialty will be addressed. This is already occurring with the European Spirometry Driving Licence. The ERS supports their general respiratory education and the growing number of allied professional members.

\section{Conclusion}

The organisation the research seminar is just the beginning in moving forward with medical education reforms and weathering the forces of change facing the profession. The ERS will respond with a renewal of its activities and educational initiatives in line with medical education theories and principles. This, we hope will support our members and the wider respiratory medicine community and is ultimately consistent with the ERS mission of alleviating suffering from respiratory disease and promoting lung health.

\section{REFERENCES}

1. Horsley T, Grimshaw J, Campbell C. Maintaining the competence of Europe's workforce. BMJ 2010; 341: c4687.

2. Irby D, Cooke M, O'Brien B. Calls for reform of medical education by the Carnegie Foundation for the Advancement of Teaching: 1910 and 2010. Acad Med 2010; 85: 220-227.

3. Loddenkemper R, Séverin T, Eiselé JL, et al. HERMES: a European core syllabus in respiratory medicine. Breathe 2006; 3: $59-70$.

4. Gappa M, Paton J, Baraldi E, et al. Paediatric HERMES: update of the European Training Syllabus for Paediatric Respiratory Medicine. Eur Respir J 2009; 33: 464-465.

5. Loddenkemper R, Haslam P, Séverin T, et al. European curriculum recommendations for training in adult respiratory medicine: 2nd report of the HERMES Task Force. Breathe 2008; 5: 80-93.

6. Gappa M, Noel J-L, Séverin T, et al. Paediatric HERMES: European curriculum recommendations for training in Paediatric Respiratory Medicine. Breathe 2010; 7: 72-79.

7. Palange P, Simonds A, eds. ERS Handbook of Respiratory Medicine. 1st Edn. Sheffield: European Respiratory Society, 2010.

8. De Backer W, Simonds A, Horn V, et al. Sleep HERMES: a European Core Syllabus in respiratory disorders during sleep. Breathe 2011; 8: 61-68.

9. Loddenkemper R, Séverin T, Mitchell $S$ et al. Adult HERMES: criteria for accreditation of ERS European training centres in adult respiratory medicine. Breathe 2010; 2: 171-188. 